\title{
Dry ice blasting as a substitution for the conventional electroplating pre-treatments
}

\author{
Eckart Uhlmann, El Mustapha Baira*, and Robert Jaczkowski \\ Institute for Machine Tools and Factory Management, Technische Universität Berlin, 10587 Berlin, Germany
}

Received 7 September 2016 / Accepted 18 November 2016

\begin{abstract}
For high quality electroplated products, surfaces must be thoroughly pre-treated. For this purpose electroplating currently needs a variety of chemical baths. The used chemicals are injurious to health and harmful to the environment. In addition, the conventional pre-treatment has a long process time which results in high costs. Dry ice blasting alone or in combination with other processes has the potential to completely substitute these conventional pre-treatment processes. Three process sequences as pre-treatment methods prior to electroplating were investigated on the aluminium alloys AlSi12 and AlMg3. The used processes are dry ice blasting, tempering during dry ice blasting and glass bead blasting followed by dry ice blasting. The influence of the parameters on the surface roughness, surface topography and surface tension of the workpieces was examined. A model to describe the correlation between the dry ice blasting parameters and surface parameters was developed. Finally, an adhesion test of electroplated specimen was conducted in order to determine the suitability of these alternative pre-treatment processes.
\end{abstract}

Key words: Coating, Electroplating, Surface analysis, Dry ice blasting

\section{Introduction}

This journal article is written on the basis of research results presented during 2nd Edition Smart Materials \& Surfaces Conference SMS KOREA 2016 that was held from 23rd to 25th March 2016 in Incheon, Republic of Korea.

Since the results of the galvanic surface treatment are highly dependent on the pre-treatment steps, no residues of grinding and blasting media should remain in and on the workpiece surface $[1,2]$. A residue-free cleaning is necessary, in order to ensure a high quality coating. Currently electroplating requires a variety of chemical baths for this purpose. Figure 1 shows a simplified schematic diagram of a conventional galvanic process chain.

\section{Materials and methods}

The chosen materials for this research are the wrought aluminium alloy AlMg3 and the casted aluminium alloy AlSi12 which can be galvanised by using the conventional pre-treatment processes, Figure 1. Both materials offer great weight saving potential and easy processing during manufacturing. Furthermore, the ability to recycle workpieces made of

*e-mail: baira@iwf.tu-berlin.de aluminium alloys reduce the use of raw materials and increase the sustainability compared to steel parts. Applications for AlMg3 are for example transport containers, whereas AlSi12 is used for thin walled housings, for example gearbox enclosures. Workpieces made of aluminium may be galvanised to achieve different appearances of the surface or to modify functional properties. AlMg3 is classified as easy to galvanize, whereas the pre-treatment of AlSi12 has to satisfy demanding requirements. Silicon particles on the surface of AlSi12 parts exposed by the conventional pre-treatment are disadvantageous for the adhesive strength of the applied layers and have to be removed by etching with nitric acid, which affects the environmental compatibility and economic efficiency negative. The samples used in this research are made of rolled aluminium plates with a thickness of $6 \mathrm{~mm}$, cut to pieces of a size of $40 \mathrm{~mm}$ by $40 \mathrm{~mm}$.

The alternative pre-treatment methods used in this research are dry ice blasting, tempering during dry ice blasting and glass bead blasting followed by dry ice blasting. Dry ice blasting is a blasting method using pressurized air as an accelerator for the blasting material. Dry ice is the solid form of carbon dioxide and is normally used in cleaning applications. Due to the sublimation of solid carbon dioxide to its gaseous physical state at standard pressure it leaves no residues when used as blasting material. Figure 2 shows the effect mechanisms of 


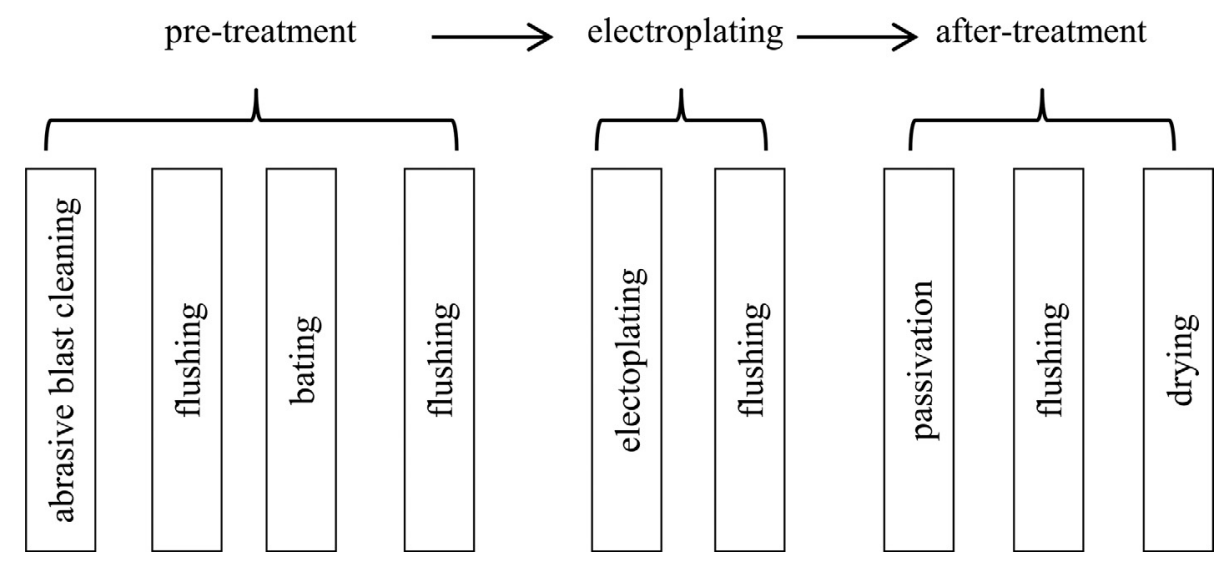

Figure 1. Schematic representation of the electroplating process [3].

(a)

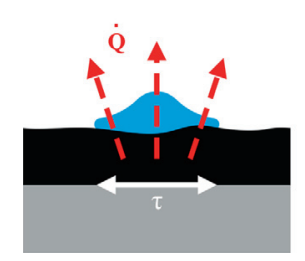

(b)

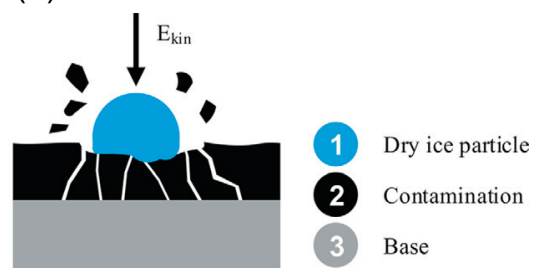

Figure 2. Effect mechanisms of dry ice blasting: (a) thermal effect, and (b) mechanical effect.

the dry ice blasting technology. A distinction is made between the thermal effect, caused by the low temperature of the blasting material resulting in an increased brittleness of the contaminations and base material and induced tensions between them, and the mechanical effect of the blasting particles due to their high speed and weight. To increase the thermal effect of the dry ice blasting and as the second pretreatment method, the aluminium samples have been tempered to a temperature of $\vartheta=50{ }^{\circ} \mathrm{C}$ before blasting, causing an increase of the temperature gradient between the samples and the blasting media.

Glass bead blasting in combination with dry ice blasting is used as the third pre-treatment method. In comparison to dry ice blasting, glass beads are used as blasting material. Although there is no thermal effect when using glass bead blasting, the overall effect on the surface of the substrate is by far higher because of the larger mechanical effect caused by the higher weight and hardness of the glass beads compared to dry ice particles. The disadvantage of the procedure is that residues of used glass beads remain on the surface of the substrate after blasting and have to be removed in a separate step to obtain galvanic coatings with high adhesive strengths. Due to the residues the workpieces could not be galvanized using solely glass bead blasting as the pre-treatment process. These residues totally prevent the realisation of galvanic coatings.

The alternative pre-treatment methods have the potential to decrease duration and costs of the pre-treatment prior to galvanic coating processes since the process chain of the conventional pre-treatment can be shortened. Dry ice blasting allows the cleaning and pre-treatment of surfaces without any residues which improves the creation of adherent coatings. The substitution of chemicals used in the conventional pre-treatment process, which are hazardous to the environment and harmful to health and therefore need an expensive waste deposal which amplifies the cost benefits of the dry ice blasting as well as its sustainability.

To determine the influence of the alternative pre-treatment methods on the roughness, topography and polar component of the surface tension of the workpieces AlSi12 and AlMg3 a Central Composite Design (CCD) was used [4]. With it linear and quadratic interrelation between the setting parameters and the target values can be defined. The utilisation of the CCD furthermore allows the creation of equations describing the target values (e.g. the roughness $R_{\mathrm{z}}$ or the polar component of the surface tension) subject to the setting parameters. The used model, equation (1), brings all target values $y$ in dependency with the main factors $x_{i}$, the interactions between the factors $x_{i} \cdot x_{j}$ and the quadratic effects of the factors $x_{i}^{2}$. The coefficients $\beta$ for each target value of the investigated materials were determined.

$$
y=\beta_{0}+\sum_{i=1}^{k} \beta_{i} \cdot x_{i}+\sum_{i<j=2}^{k} \beta_{i j} \cdot x_{i} \cdot x_{j}+\sum_{i=1}^{k} \beta_{i i} \cdot x_{i}^{2}+\varepsilon
$$

The dry ice blasting was undertaken with an IceBlast KG 30 Professional system from Ice Tech. Table 1 shows the ranges of the setting parameters during dry ice blasting. Surface and coating parameters were recorded to compare the pre-treatment methods. The roughness of the workpieces were measured utilizing the measuring instrument MicroProf 100 by FRT Fries Research \& Technology GmbH, Bergisch Gladbach, Germany. Using the sessile drop method and the Drop Shape Analyzer DSA 100 by Krüss GmbH, Hamburg, Germany, the surface tension and its polar component were determined. To verify the adhesion strength of the applied coatings, the standardized method of the cross cutting index, compare DIN EN ISO 2409, was used. The cross cutting index provides information on the adhesion strength by distinguishing the amount of coating that is removed after the peel of the adhesive 
Table 1. Ranges of the setting parameters during dry ice blasting.

\begin{tabular}{|c|c|c|c|c|c|}
\hline Setting parameters & Jet pressure $p_{\text {st }}[\mathrm{bar}]$ & Mass flow rate $\dot{m}[\mathrm{~kg} / \mathrm{h}]$ & Working distance $a_{\mathrm{p}}[\mathrm{mm}]$ & Feed velocity $v_{\mathrm{f}}[\mathrm{m} / \mathrm{s}]$ & Jet angle $\alpha\left[^{\circ}\right]$ \\
\hline Ranges & $6-10$ & $35-65$ & $50-100$ & $0.005-0.015$ & $50-80$ \\
\hline
\end{tabular}

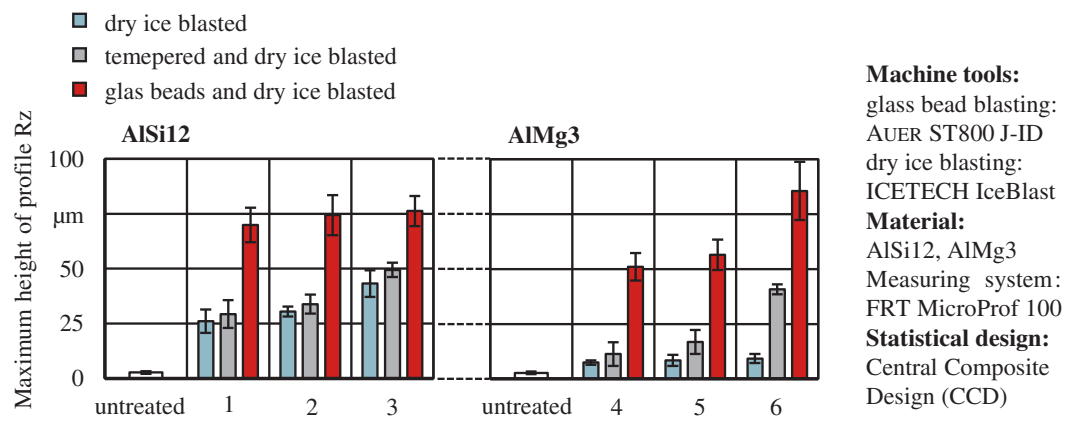

Setting parameters:
\begin{tabular}{|c|c|c|c|c|c|}
\hline & $\begin{array}{c}\text { Jet } \\
\text { pressure } \\
\mathrm{p}_{\mathrm{st}}[\mathrm{bar}]\end{array}$ & $\begin{array}{c}\text { Mass } \\
\text { flow rate } \\
\dot{\mathrm{m}}[\mathrm{kg} / \mathrm{h}]\end{array}$ & $\begin{array}{c}\text { Working } \\
\text { distance } \\
\mathrm{a}_{\mathrm{p}}[\mathrm{mm}]\end{array}$ & $\begin{array}{c}\text { Feed } \\
\text { velocity } \\
\mathrm{v}_{\mathrm{f}}[\mathrm{m} / \mathrm{s}]\end{array}$ & $\begin{array}{c}\text { Jet angle } \\
\alpha\left[{ }^{\circ}\right]\end{array}$ \\
\hline 1 & 10 & 65 & 75 & 0.01 & 90 \\
\hline 2 & 10 & 35 & 100 & 0.005 & 80 \\
\hline 3 & 8 & 50 & 75 & 0.0018 & 65 \\
\hline 4 & 10 & 35 & 100 & 0.005 & 80 \\
\hline 5 & 11.4 & 50 & 75 & 0.01 & 65 \\
\hline 6 & 8 & 50 & 75 & 0.0018 & 65 \\
\hline
\end{tabular}

Figure 3. Exemplary results of the roughness $R_{\mathrm{z}}$ of AlSi12- and AlMg3-workpieces after alternative pre-treatment.

Table 2. Coefficients $\beta$ for regression equation of effects on the roughness $R_{\mathrm{z}}$ of dry ice blasted AlSi12-workpieces.

\begin{tabular}{cccccc}
\hline Setting parameter & Coefficient $\beta$ & Setting parameter & Coefficient $\beta$ & Setting parameter & Coefficient $\beta$ \\
\hline Constant $\beta_{0}$ & -68.357 & $\dot{m}^{2}$ & -0.00517199 & $\mathrm{p}_{\mathrm{st}} \cdot \alpha$ & 0.0221865 \\
$p_{\text {st }}$ & 6.07127 & $a_{\mathrm{p}}{ }^{2}$ & -0.00228115 & $\dot{m} \cdot a_{\mathrm{p}}$ & -0.000159028 \\
$\dot{m}$ & 0.510387 & $v_{\mathrm{f}}$ & 124518 & $\dot{m} \cdot v_{\mathrm{f}}$ & 6.07181 \\
$a_{\mathrm{p}}$ & 0.357934 & $\alpha^{2}$ & -0.00544859 & $\dot{m} \cdot \alpha$ & 0.000525509 \\
$v_{\mathrm{f}}$ & -1797.9 & $p_{\mathrm{st}} \cdot \dot{m}$ & -0.0110615 & $a_{\mathrm{p}} \cdot v_{\mathrm{f}}$ & -0.307417 \\
$\alpha$ & 0.982878 & $p_{\mathrm{st}} \cdot a_{\mathrm{p}}$ & 0.014656 & $a_{\mathrm{p}} \cdot \alpha$ & -0.00134764 \\
$p_{\text {st }}^{2}$ & -0.301857 & $p_{\mathrm{st}} \cdot v_{\mathrm{f}}$ & -167.805 & $v_{\mathrm{f}} \cdot \alpha$ & -9.45181 \\
\hline
\end{tabular}

tape. A cross cutting index of 0 stands for no detachments of the coating and therefore best adhesion strength, whereas at a cross cutting index of 5 the coating detaches completely from the substrate.

\section{Results}

The following section presents the influence of the alternative pre-treatment methods on the surface of the tested aluminium alloys AlSi12 and AlMg3. According to state of technology the maximum height of profile $R_{\mathrm{z}}$, the topography as well as the polar component of the surface tension $\sigma_{\mathrm{SP}}$ have a significant impact on the adhesion of the metal layer.

\subsection{Influence of the pre-treatment methods on the roughness $R_{\mathrm{z}}$ of the aluminium alloys}

According to the mechanical anchoring model, the adhesion of the subsequent coating gets better with higher surface roughnesses $[5,6]$. Figure 3 shows the three highest achieved roughnesses $R_{\mathrm{z}}$ after the treatment with dry ice blasting, tempering during dry ice blasting and glass bead blasting followed by dry ice blasting. All three pre-treatment methods increased the roughness of the AlSi12-workpieces. The maximum height of profile $R_{\mathrm{z}}$ of an untreated AlSi12-workpiece was $R_{\mathrm{z}}=2.78 \mu \mathrm{m}$, dry ice blasting increased it to $R_{\mathrm{z}}=43.26 \mu \mathrm{m}$, tempering during dry ice blasting to $R_{\mathrm{z}}=49.46 \mu \mathrm{m}$ and glass bead blasting with following dry ice blasting produced the highest roughness of $R_{\mathrm{z}}=76.22 \mu \mathrm{m}$. $\mathrm{AlMg} 3$ has an original roughness of $R_{\mathrm{z}}=2.55 \mu \mathrm{m}$. Dry ice blasting increased it only to $R_{\mathrm{z}}=9.30 \mu \mathrm{m}$, tempering during dry ice blasting to $R_{\mathrm{z}}=40.75 \mu \mathrm{m}$ and the highest roughness was also achieved by glass bead blasting with following dry ice blasting up to $R_{\mathrm{z}}=85.51 \mu \mathrm{m}$. So, as expected glass bead blasting produced the highest roughness of both aluminium alloys. Additionally, the roughness can be increased by lowering feed velocity $v_{\mathrm{f}}$ of the blasting process.

Models of the different materials and pre-treatment processes, equation (1), have been developed and significant setting parameters have been identified. As an example, Table 2 contains the coefficients $\beta$ of the regression analysis of the roughness $R_{\mathrm{z}}$ for dry ice blasted AlSi12-worpieces. In this case, the significant parameters are the feed velocity $v_{\mathrm{f}}$ and its quadratic effect, the jet angle $\alpha$ and the jet pressure $p_{\text {st }}$.

\subsection{Influence of the pre-treatment methods on topography of the aluminium alloys}

Dry ice blasting and tempering to $50{ }^{\circ} \mathrm{C}$ during dry ice blasting lead to a change of the topography of the AlSi12workpieces. On the other hand these two methods almost did not change the topography of the AlMg3-workpieces. Glass bead blasting with following dry ice blasting changed the topography of both aluminium alloys which resulted in visible impact craters, shown in Figure 4. 

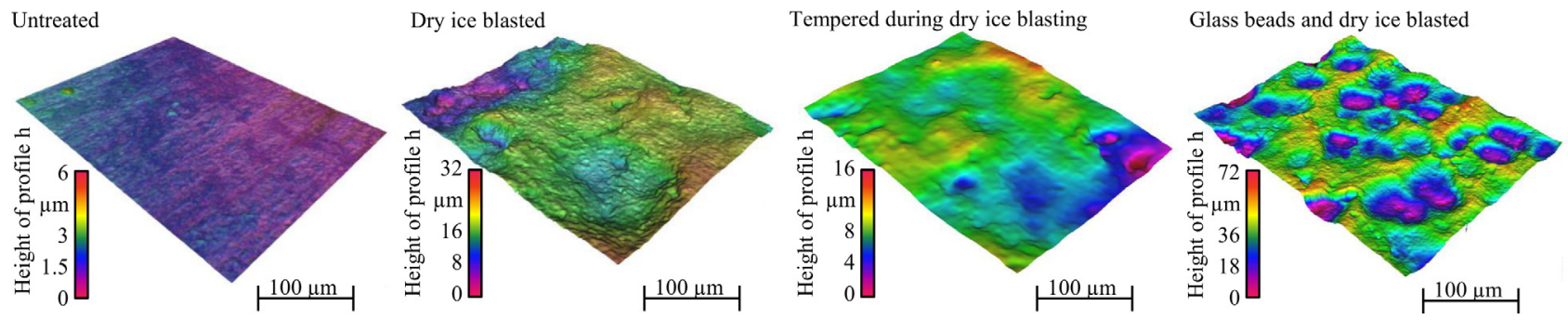

Figure 4. Topography images of AlSi12-workpieces.
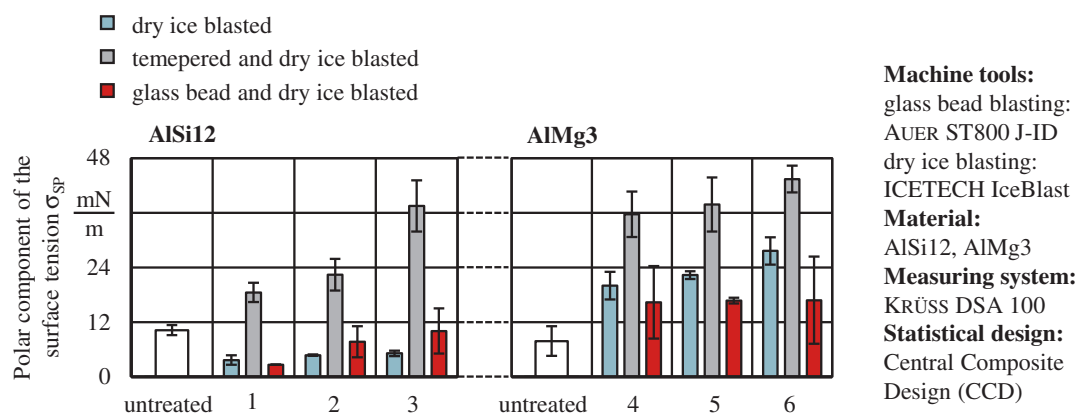

Setting parameters:
\begin{tabular}{|c|c|c|c|c|c|}
\hline & $\begin{array}{c}\text { Jet } \\
\text { pressure } \\
\mathrm{p}_{\mathrm{st}}[\mathrm{bar}]\end{array}$ & $\begin{array}{c}\text { Mass } \\
\text { flow rate } \\
\dot{\mathrm{m}}[\mathrm{kg} / \mathrm{h}]\end{array}$ & $\begin{array}{c}\text { Working } \\
\text { distance } \\
\mathrm{a}_{\mathrm{p}}[\mathrm{mm}]\end{array}$ & $\begin{array}{c}\text { Feed } \\
\text { velocity } \\
\mathrm{v}_{\mathrm{f}}[\mathrm{m} / \mathrm{s}]\end{array}$ & $\begin{array}{c}\text { Jet angle } \\
\alpha\left[{ }^{\circ}\right]\end{array}$ \\
\hline 1 & 6 & 65 & 50 & 0.015 & 80 \\
\hline 2 & 8 & 50 & 35 & 0.01 & 65 \\
\hline 3 & 8 & 50 & 115 & 0.01 & 65 \\
\hline 4 & 10 & 35 & 100 & 0.005 & 80 \\
\hline 5 & 11.4 & 50 & 75 & 0.01 & 65 \\
\hline 6 & 8 & 30 & 75 & 0.01 & 65 \\
\hline
\end{tabular}

Figure 5. Exemplary results of polar component of the surface tension $\sigma_{\mathrm{SP}}$ of AlSi12- and AlMg3-workpieces after alternative pre-treatment.

Table 3. Coefficients $\beta$ for regression equation of effects on the polar component of the surface tension $\sigma_{\mathrm{SP}}$ of dry ice blasted AlSi12workpieces.

\begin{tabular}{cccccc}
\hline Setting parameter & Coefficient $\beta$ & Setting parameter & Coefficient $\beta$ & Setting parameter & Coefficient $a$ \\
\hline Constant $\beta_{0}$ & 13.5082 & $\dot{m}^{2}$ & 0.00440098 & $p_{\text {st }} \cdot \alpha$ & 0.00021829 \\
$p_{\text {st }}$ & 1.00959 & $a_{\mathrm{p}}{ }^{2}$ & -0.0008924 & $\dot{m} \cdot a_{\mathrm{p}}$ & -0.00115788 \\
$\dot{m}$ & -0.514775 & $v_{\mathrm{f}}$ & 5498.54 & $\dot{m} \cdot v_{\mathrm{f}}$ & 8.76962 \\
$a_{\mathrm{p}}$ & 0.259321 & $\alpha^{2}$ & 0.000692277 & $\dot{m} \cdot \alpha$ & 0.00037707 \\
$v_{\mathrm{f}}$ & -1043.4 & $p_{\text {st }} \cdot \dot{m}$ & 0.00725405 & $a_{\mathrm{p}} \cdot v_{\mathrm{f}}$ & -3.11292 \\
$\alpha$ & -0.165747 & $p_{\mathrm{st}} \cdot a_{\mathrm{p}}$ & -0.00298707 & $a_{\mathrm{p}} \cdot \alpha$ & -0.00038179 \\
$p_{\mathrm{st}}^{2}$ & -0.113682 & $p_{\mathrm{st}} \cdot v_{\mathrm{f}}$ & 44.7577 & $v_{\mathrm{f}} \cdot \alpha$ & 4.6968 \\
\hline
\end{tabular}

\subsection{Influence of the pre-treatment methods on the polar component of the surface tension of the aluminium alloys}

Previous investigations have shown that better adhesion strengths can be achieved with high polar components of the surface tension $\sigma_{\mathrm{SP}}[5,6,7,8]$. The surface tension can therefore be used as an indicator for the adhesion strength of the electrodeposited coatings. Only tempering during dry ice blasting increased the polar component of the surface tension $\sigma_{\mathrm{SP}}$ of the AlSi12-workpieces from $\sigma_{\mathrm{SP}}=10.26 \mathrm{mN} / \mathrm{m}$ to $\sigma_{\mathrm{SP}}=37.49 \mathrm{mN} / \mathrm{m}$, which implies a heterogeneous wetting of the substrate. The polar component of the surface tension of AlMg3-workpieces was increased by all three pre-treatment methods, Figure 5. So the fluid penetrates the more hydrophilic surface (Wenzel-model) resulting in a homogeneous wetting. Tempering during dry ice blasting produced the highest polar component of the surface tension with $\sigma_{\mathrm{SP}}=43.44 \mathrm{mN} / \mathrm{m}$.
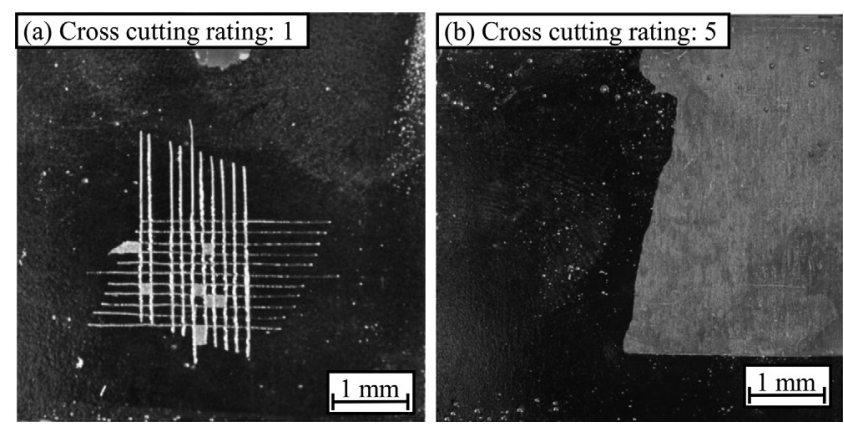

Figure 6. Exemplarily cross cutting ratings of AlSi12: (a) sufficient adhesion, and (b) poor adhesion.

Analogous to the roughness $R_{\mathrm{z}}$, models for the polar component of the surface tension $\sigma_{\mathrm{SP}}$, equation (1), have been developed. The coefficients $\beta$ for the model for the dry ice blasted workpieces are contained in Table 3 . In this case, just 

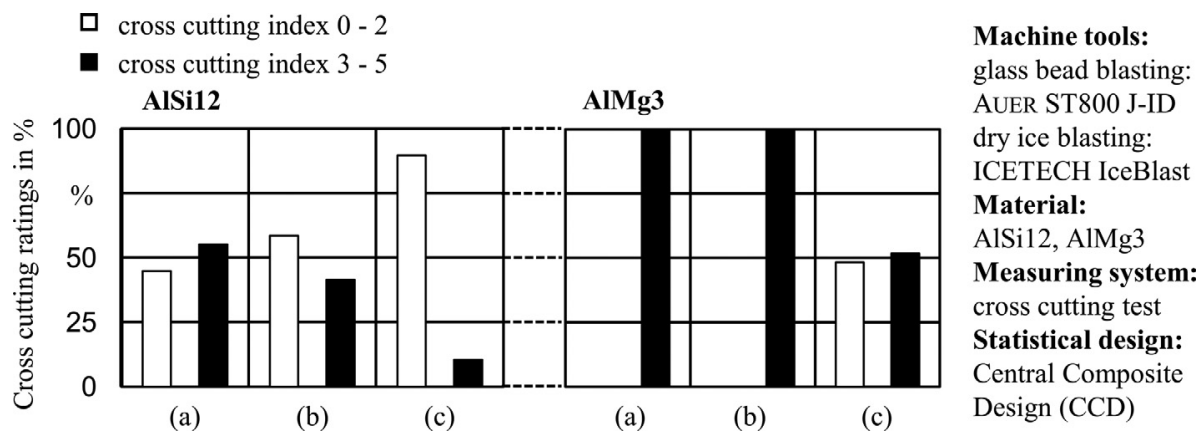

Figure 7. Cross cutting ratings of AlSi12 and AlMg3: (a) after dry ice blasting, (b) after tempering during dry ice blasting, and (c) after glass bead blasting with following dry ice blasting.

the quadratic effect of the mass flow rate $\dot{m}^{2}$ is significant for the polar component of the surface tension $\sigma_{\mathrm{SP}}$.

\subsection{Adhesion test after electroplating of the aluminium alloys}

After the electroplating process the cross cutting index was used as an indicator for the adhesion of the electroplating coat. The cross cutting index between 0 und 2 means that the adhesion was good and the cross cutting index $\geq 3$ means that the adhesion was insufficient. Figure 6 shows two results of the adhesion test of the applied galvanised coatings on AlSi12 workpieces, which have been dry ice blasted as pre-treatment.

Dry ice blasting and tempering during dry ice blasting result in good adhesion (cross cutting index between 0 and 2) with $50 \%$ of all the examined parameter settings of the AlSi12-workpieces. After glass bead blasting with following dry ice blasting almost $90 \%$ of the workpieces were successfully electroplated. $50 \%$ of the $\mathrm{AlMg} 3$-workpieces achieved good adhesion after glass bead blasting with following dry ice blasting, Figure 7 . With the detected parameter combinations which enable a sufficient adhesion, the pre-treatment of the workpieces prior to the galvanization could be enabled with a high process reliability and repeatability.

\section{Discussion}

It was found that the polar component of the surface tension has no significant effect on the adhesion of the electroplated layers. The roughness and the surface topography however have a significant influence on the adhesion after the electroplating. With dry ice blasting a successful electroplating of AlSi12 samples was achieved. Based on the entire investigations, the pre-treatment with dry ice blasting is considered to be a suitable substitution to other pre-treatment for AlSi12 workpieces methods in order to further enhance the adhesive strength. The pre-treatment of AlMg3 workpieces could not be successfully executed resulting in a worse adhesion of the applied galvanised coating compared to the pre-treatment of AlSi12 workpieces. This circumstance needs further examination and analysis.

The results of this research should be used to expand the range of materials, which can be pre-treated successfully by the alternative pre-treatment methods. In particular, the alternative pre-treatment methods should be applied to steel workpieces and workpieces made of materials, which are difficult to galvanize, such as carbon fibre composites.

Acknowledgements. This paper is based on the results acquired in the project DFG UH 100/154-1, which is kindly supported by the German Research Foundation (DFG). Furthermore the author would like to thank the company which participated in this research project.

\section{References}

1. E. Uhlmann, E.M. Baira, M. Kretzschmar, Trockeneis statt Beizen, Journal für Oberflächentechnik (JOT) 9 (2013) 60-63.

2. H. Narcus, Metallizing of plastics, Reinhold Publishing Corp, New York, 1960.

3. T.W. Jelinek, Praktische Galvanotechnik, 7. Auflage, Eugen G. Leuze Verlag, Bad Saulgau, 2013.

4. R.J. Del Vecchio, Design of experiments, Carl Hanser Verlag, München, 1997.

5. R. Suchentrunk et al., Kunststoff-Metallisierung, Eugen G. Leuze Verlag, Bad Saulgau, 2007.

6. W. Brockmanm (Hrsg.), Haftung als Basis für Stoffverbunde und Verbundwerkstoffe, Deutsche Gesellschaft für Metallkunde e.V, Oberursel, 1990.

7. H. Gleich, Zusammenhang zwischen Oberflächenenergie und Adhäsionsvermögen von Polymerwerkstoffen am Beispiel von PP und PBT und deren Beeinflussung durch die NiederdruckPlasmatechnologie, Dissertation, Universität Duisburg-Essen, 2004.

8. T. Hühns, Charakterisierung und Auslegung der Grenzschicht PVD-beschichteter Schneidkeramiken, in: E. Uhlmann (Hrsg.), Berichte aus dem Produktionstechnischen Zentrum Berlin, Fraunhofer-Verlag, Stuttgart, 2010. 